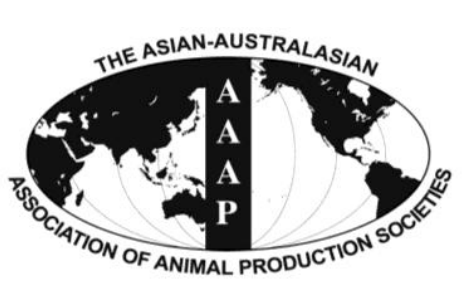

Open Access

Asian Australas. J. Anim. Sci.

Vol. 27, No. 6 : 907-915 June 2014

http://dx.doi.org/10.5713/ajas.2013.13588

www.ajas.info

pISSN 1011 -2367 elSSN 1976-5517

\title{
Protective Efficacy of Alpha-lipoic Acid against AflatoxinB1-induced Oxidative Damage in the Liver
}

\author{
Y. Li ${ }^{\text {a }}$, Q. G. Ma ${ }^{\text {a }}$ L. H. Zhao, Y. Q. Guo ${ }^{1}$, G. X. Duan, J. Y. Zhang, and C. Ji* \\ State Key Laboratory of Animal Nutrition, College of Animal Science and Technology, \\ China Agricultural University, Beijing 100193, China
}

\begin{abstract}
Alpha-lipoic acid ( $\alpha$-LA) is not only involved in energy metabolism, but is also a powerful antioxidant that can protect against hepatic oxidative stress induced by some drugs, toxins, or under various physiological and pathophysiological conditions. Here, we investigated the effect of $\alpha$-LA against liver oxidative damage in broilers exposed to aflatoxin $\mathrm{B}_{1}\left(\mathrm{AFB}_{1}\right)$. Birds were randomly divided into four groups and assigned different diets: basal diet, $300 \mathrm{mg} / \mathrm{kg} \alpha$-LA supplementation in basal diet, diet containing $74 \mu \mathrm{g} / \mathrm{kg}$ $\mathrm{AFB}_{1}$, and $300 \mathrm{mg} / \mathrm{kg} \alpha-\mathrm{LA}$ supplementation in diet containing $74 \mu \mathrm{g} / \mathrm{kg} \mathrm{AFB}{ }_{1}$, for 3 weeks. The results revealed that the addition of $300 \mathrm{mg} / \mathrm{kg} \alpha$-LA protected against the liver function damage of broilers induced by chronic low dose of $\mathrm{AFB}_{1}$ as estimated by a significant $(\mathrm{p}<0.05)$ change in levels of plasma total protein, albumin, alkaline phosphatase and the activities of liver glutamic-oxalacetic transaminase and glutamic-pyruvic transaminase. The histopathological analysis also showed that liver tissues were injured in the $\mathrm{AFB}_{1}$ diet, but this effect was alleviated by the addition of $300 \mathrm{mg} / \mathrm{kg} \alpha$-LA. Additionally, $\mathrm{AFB}_{1}$ induced a profound elevation of oxidative stress in birds, as indicated by an increase in malondialdehyde level, a decrease in glutathione peroxidase activity and a depletion of the glutathione content in the liver. All of these negative effects were inhibited by treatment with $\alpha$-LA. Our results suggest that the inhibition of $\mathrm{AFB}_{1}$-induced excess production of lipid peroxides and the maintenance of intracellular antioxidant status may play important roles in the protective effects of $\alpha$-LA against $\mathrm{AFB}_{1}$-induced oxidative damage in the liver. (Key Words: AflatoxinB1, Alpha-lipoic Acid, Liver, Oxidative Damage, Antioxidant)
\end{abstract}

\section{INTRODUCTION}

It is reported that at least $25 \%$ of the world's grains are contaminated with mycotoxins (Surai, 2006). Aflatoxins $(\mathrm{AFs})$ are known to be very dangerous mycotoxins, with high toxicity to both animals and humans, and are produced mainly by Aspergillus flavus, A. parasiticus, and some other species of Aspegillus, Penicilium, and Rhizopus (Wogan, 1973; Bennett and Klich, 2003). Aflatoxin $\mathrm{B}_{1}\left(\mathrm{AFB}_{1}\right)$ is considered the most biologically active form of AFs

\footnotetext{
* Corresponding Author: C. Ji. Tel: +86-10-62731998, Fax: +8610-62731998, E-mail: jicheng@cau.edu.cn

${ }^{1}$ Animal Science and Technology College, Beijing University of Agriculture, Beijing 102206, China.

${ }^{\text {a }}$ Y. Li and Q. G. Ma are the co-first authors.

Submitted Sept. 19, 2013; Revised Dec. 24, 2013; Accepted Jan. 9, 2014
}

(Kubena et al., 1993; Ledoux et al., 1999). The carcinogenicity, teratogenicity, and immunosuppressive effects caused by this toxin are harmful to the health of humans and animals (Gao et al., 2011). Animals suffering from aflatoxicosis exhibit various clinical signs, including lethargy, anorexia, and poor performance, as well as damage to tissues (Nibbelink, 1986; Pier, 1992). One of the negative impacts of $\mathrm{AFB}_{1}$ is cell and tissue injury, which produces free radicals and lipid peroxides (Surai, 2002). Some reports suggest that $\mathrm{AF}_{\mathrm{S}}$, possibly associated with the induction of oxidative stress, may be responsible for mediating various toxic effects in tissues (Barraud et al., 2001; Liu et al., 2008; Umarani et al., 2008). Therefore, some antioxidants might protect against AF-induced tissue damage through modulation of the detoxification and antioxidant systems (Coulombe et al., 2005).

Lipoic acid (LA), a dithiol compound derived from

Copyright (? 2014 by Asian-Australasian Journal of Animal Sciences This is an open-access article distributed under the terms of the Creative Commons Attribution Non-Commercial License (http://creativecommons.org/licenses/by-nc/3.0/), which permits unrestricted non-commercial use, distribution, and reproduction in any medium, provided the original work is properly cited. 
octanoic acid, is a fatty acid that functions as a cofactor in vital energy-producing reactions and thus plays a major role in energy metabolism. As the "universal antioxidant", LA and its reduced form, dihydrolipoate, are metal chelators and scavenge several types of free radicals, and regenerate other antioxidants, such as ascorbate, Vitamin E and glutathione (GSH) (Packer et al., 1995; Bilska and Wlodek, 2005). Previous studies from our laboratory have shown that addition of alpha-lipoic acid ( $\alpha$-LA) to diets could enhance the antioxidant capability of broilers (Zhang et al., 2009; Chen et al., 2011) and piglets (Bai et al., 2012). Therefore, $\alpha$-LA has been used in the prevention or treatment of several pathological conditions that are mediated by oxidative stress. Sherry and Rogers (2003) reported that $\alpha$-LA is a potential agent to protect against mycotoxins and treat mycotoxicoses such as mushroom poisoning. In addition, Karaman et al. (2010) reported that feeding with $60 \mathrm{mg} / \mathrm{kg}$ per body weight (BW) LA might ameliorate the degenerative effects caused by AF (150 and $300 \mathrm{ppb}$ ) because of lipid peroxidation. Meanwhile, in our previous study, supplementation of 600 and $900 \mathrm{mg} / \mathrm{kg} \mathrm{LA}$ (about 52 and $78 \mathrm{mg} / \mathrm{kg} / \mathrm{BW}$, respectively) in broiler diet without AF contamination significantly reduced the average daily feed intake and average daily weight gain, but 300 $\mathrm{mg} / \mathrm{kg}$ LA enhanced antioxidant capability of broilers while having no adverse effect on growth performance (Zhang et al., 2009). Hence, we speculated that the addition of 300 $\mathrm{mg} / \mathrm{kg} \alpha$-LA to the diet could alleviate $\mathrm{AFB}_{1}$-induced toxicity by mediating the animal body redox regulation and antioxidant systems, without adverse effect on growth performance.

In keeping with the above views, our objective was to examine the detoxification efficacy of $\alpha$-LA in ameliorating $\mathrm{AFB}_{1}$-induced oxidative damage in broiler chickens.

\section{MATERIALS AND METHODS}

\section{Collection of feed ingredients contaminated with aflatoxin $B_{1}$}

A total of 100 feed ingredients were sampled in the scope of the nation, and the contents of mycotoxins including $\mathrm{AFB}_{1}$, deoxynivalenol, zearalenone, and ochratoxin A were tested using high performance liquid chromatography (HPLC) according to the method of Trucksess et al. (1994). Two samples of AFB-free peanut meal and peanut meal seriously contaminated with $\mathrm{AFB}_{1}$ (330 $\mu \mathrm{g} / \mathrm{kg}$ ) were selected and incorporated into the basal diet by proportion.

\section{Animals}

One-day-old male broiler chickens (Ross 308) were obtained from a commercial hatchery (Chia Tai Co., Ltd,
Hebei, China). The brooding temperature was maintained at $35^{\circ} \mathrm{C}$ and $65 \%$ relative humidity ( $\left.\mathrm{RH}\right)$ for the first 2 days, and then decreased gradually to $21^{\circ} \mathrm{C}(45 \% \mathrm{RH})$ until 28 days and maintained as such until the end of the experiment. The light regime was $23 \mathrm{~L}: 1 \mathrm{D}$. All chicks were provided $a d$ libitum to water and a commercial diet during the rearing period. The animal care protocol in this experiment was according to commercial management practice, and approved by the Animal Welfare Committee of China Agricultural University.

\section{Experimental design}

After a $10 \mathrm{~d}$ adaption period to the diet and surrounding, a total of 160 eleven-day-old birds with similar BW were randomly assigned to 4 groups with 4 replicates pens of 10 birds per pen. Four treatment groups included: fed the basal diet with $21 \%$ normal peanut meal (no mycotoxin) (control); administered with $300 \mathrm{mg} / \mathrm{kg}$ DL- $\alpha$-LA (Sigma Chemical, St. Louis, MO, USA) supplementation in the basal diet; fed the diet containing $74 \mu \mathrm{g} / \mathrm{kg}$ AFB $_{1}(21 \%$ moldy peanut meal naturally contaminated with $330 \mu \mathrm{g} / \mathrm{kg}$ $\mathrm{AFB}_{1}$ substituted for normal peanut meal by the same proportion in basal diet); and fed the diet supplemented with $300 \mathrm{mg} / \mathrm{kg} \alpha-\mathrm{LA}$ and $\mathrm{AFB}_{1}$ (determined $74 \mu \mathrm{g} / \mathrm{kg}$ $\mathrm{AFB}_{1}$ without other mycotoxins). All essential nutrients in the basal diet (Table 1) met or were slightly lower than the nutrient requirements of National Research Council (1994). The composition of diets and the content of $\mathrm{AFB}_{1}$ in the diets are shown in Table 1. The feeding trial period lasted for 3 weeks.

At the end of the experiment, eight chicks with body weights close to the average were selected from per treatment. After a 12 hours feed withdrawal, blood sample was drawn from a wing vein with a heparinised syringe within $30 \mathrm{~s}$ and then transferred to iced tubes. Plasma was obtained from the blood by centrifugation at 3,000 $\mathrm{g}$ for 10 min and was stored at $-20^{\circ} \mathrm{C}$ for further biochemical analysis. All chickens were sacrificed for tissue collection after blood sample collection (Cai et al., 2009). The liver tissue samples were washed with ice-cold sterilized saline $(0.85 \%)$, snap frozen in liquid nitrogen and stored at $-80^{\circ} \mathrm{C}$ for further analysis of liver metabolic enzymes and antioxidant indices.

\section{Measurements}

Histological analysis: The degrees of hepatic damage were observed with hematoxylin and eosin staining as described in Wang et al. (2003). Sections were examined under an Olympus CX-41 phase contrast microscope (Olympus, Tokyo, Japan).

Plasma parameters analysis: The concentrations of uric acid (UA), creatinine (CREA), calcium (Ca), total protein 
Table 1. Composition of the diets during the experiment

\begin{tabular}{|c|c|}
\hline Item & Composition \\
\hline \multicolumn{2}{|l|}{ Ingredient (\%) } \\
\hline Corn & 57.7 \\
\hline Expanded soybean & 6.00 \\
\hline Soybean meal & 8.20 \\
\hline Peanut meal ${ }^{1}$ & 21.0 \\
\hline Limestone & 1.30 \\
\hline Dicalcium phosphate & 1.80 \\
\hline Salt & 0.30 \\
\hline Corn oil & 2.00 \\
\hline Lysine $(98.5 \%)$ & 0.47 \\
\hline DL-methionine & 0.36 \\
\hline Threonine & 0.19 \\
\hline Salinomycin & 0.07 \\
\hline Choline chloride & 0.10 \\
\hline $15 \%$ chlortetracycline & 0.07 \\
\hline Mordenzeo & 0.11 \\
\hline Vitamin premix ${ }^{2}$ & 0.03 \\
\hline Mineral premix ${ }^{3}$ & 0.30 \\
\hline Total & 100 \\
\hline \multicolumn{2}{|l|}{ Nutrition component } \\
\hline $\mathrm{ME}(\mathrm{MJ} / \mathrm{kg})$ & 12.55 \\
\hline $\mathrm{CP}(\%)$ & 21.5 \\
\hline Calcium (\%) & 0.99 \\
\hline Total phosphorus (\%) & 0.65 \\
\hline Nonphytate phosphorus (\%) & 0.43 \\
\hline Methionine (\%) & 0.62 \\
\hline Methionine+cystine (\%) & 0.91 \\
\hline Lysine (\%) & 1.17 \\
\hline Tryptophan (\%) & 0.21 \\
\hline Threonine $(\%)$ & 0.82 \\
\hline $\mathrm{AFB}_{1}(\mu \mathrm{g} / \mathrm{kg})$ & $0 / 0 / 74.36 / 73.44^{4}$ \\
\hline
\end{tabular}

$\mathrm{ME}$, metabolizable energy; $\mathrm{CP}$, crude protein; $\mathrm{AFB}_{1}$, aflatoxin $\mathrm{B}_{1}$.

${ }^{1}$ AFB-free peanut meal was replaced by AFB-contaminated peanut meal according to the same proportion in trail diets.

${ }^{2}$ Provided per kilogram of diet: vitamin A, 15,000 IU; cholecalciferol, $3000 \mathrm{IU}$; vitamin E, $20 \mathrm{IU}$; vitamin $\mathrm{K}_{3}, 2.18 \mathrm{mg}$; thiamine, $2.15 \mathrm{mg}$; riboflavin, $8.00 \mathrm{mg}$; pyridoxine, $4.40 \mathrm{mg}$; vitamin $\mathrm{B}_{12}, 0.02 \mathrm{mg}$; Calcium pantothenate, $25.60 \mathrm{mg}$; nicotinic acid, $65.80 \mathrm{mg}$; folic acid, $0.96 \mathrm{mg}$; biotin, $0.20 \mathrm{mg}$.

${ }^{3}$ Provided per kilogram of diet: Fe, $109.58 \mathrm{mg}$; Cu, $8.14 \mathrm{mg}$; Zn, 78.04 $\mathrm{mg}$; Mn, $105.00 \mathrm{mg}$; I, $0.34 \mathrm{mg}$; Se, $0.14 \mathrm{mg}$; choline chloride, 1,500 $\mathrm{mg}$

${ }^{4}$ Four analysis values of $\mathrm{AFB}_{1}$ came from Control, alpha-lipoic acid $(\mathrm{ALA}), \mathrm{AFB}_{1}$ and $\mathrm{ALA}+\mathrm{AFB}_{1}$ groups, respectively.

(TP) and albumin (ALB) in the blood plasma were measured spectrophotometrically using commercial diagnostic kits (Nanjing Jiancheng Bioengineering Institute, China). Alkaline phosphatase (AKP) activity was quantitatively assayed using an AKP detection kit (Nanjing Jiancheng Bioengineering Institute, China) at $520 \mathrm{~nm}$ with a spectrophotometer. The $\gamma$-glutamyl transferase $(\gamma$-GT) activity was measured using a commercial assay kit
(Nanjing Jiancheng Bioengineering Institute, China), it catalyzed the release of 5-amino-2-nitrobenzoate that was measured at $405 \mathrm{~nm}$ using a spectrophotometer.

Assay of metabolic enzyme and antioxidant indices in liver: Liver tissue $(1 \mathrm{~g})$ was cut into small pieces and homogenised in ice-cold saline buffer $(0.85 \%, \mathrm{pH}=7.4)$ (1:9, wt/v) with an Ultra-Turrax (T8, IKA-labortechnik Staufen, Germany) to form homogenates at a concentration of $0.1 \mathrm{~g} / \mathrm{mL}$ for further analysis. Liver homogenates were centrifuged at $1,000 \mathrm{~g}$ for $15 \mathrm{~min}$ at $4^{\circ} \mathrm{C}$, and the supernatants were collected. The supernatants were used for the assays of glutamic-oxalacetic transaminase (GOT), glutamic-pyruvic transaminase (GPT), total antioxidant capacity (T-AOC), total superoxide dismutase (T-SOD), catalase (CAT), glutathione reductase (GR), glutathione peroxidase $\left(\mathrm{GSH}-\mathrm{P}_{\mathrm{X}}\right)$, malondiadehyde (MDA) and GSH. The assays were determined with the clinical chemistry assay kits (Nanjing Jiancheng Bioengineering Institute, China) according to the manufacturer's recommended procedure.

The activities of GOT and GPT in liver were measured according to the method described by Henry and Golub (1960) using chemical assay kits. In brief, GOT acted on L-aspartate and $\alpha$-ketoglutaric acid to yield oxaloacetate that subsequently reacted with 2,4-dinitrophenylhy-drazine to generate red-brown colored 2,4- dinitrophenylhy-drazone which was detected at $505 \mathrm{~nm}$ using a spectrophotometer; GPT acted on L-aspartate and $\alpha$-ketoglutaric acid to yield pyruvate that subsequently reacted with 2,4dinitrophenylhy-drazine to generate red-brown colored 2,4dinitrophenylhy-drazone which was detected at $505 \mathrm{~nm}$ using a spectrophotometer.

MDA concentration was analyzed by the thiobarbituric acid method (Ohkawa et al., 1979), reading the absorbance at $532 \mathrm{~nm}$ with the spectrometer, result was expressed as $\mathrm{nmol} / \mathrm{mg}$ protein. GSH content was detected using dithionitrobenzoic acid reagent (Griffith, 1980) and the absorbance at $420 \mathrm{~nm}$ was measured, GSH content was expressed as mg GSH per $\mathrm{g}$ protein. The T-AOC was determined by the ferric reducing/antioxidant power assay and detected at $520 \mathrm{~nm}$ using a spectrophotometer, as described by Benzie and Strain (1999). SOD activity was assayed by the xanthine oxidase method (Winterbourn et al., 1975), which monitor the degree of inhibition of nitroblue tetrazolium reduction by $\mathrm{O}_{2}$-generated by xanthine and xanthine oxidase, the absorbance was read at $550 \mathrm{~nm}$ using a spectrophotometer. CAT activity was determined by measuring the decomposition of $\mathrm{H}_{2} \mathrm{O}_{2}$ at $240 \mathrm{~nm}$. GR activity was measured by the method of Carlberg and Mannervik (1975) by measuring the rate of nicotinamide adenine dinucleotide phosphate oxidation as measured decrease in absorbance at $340 \mathrm{~nm}$ with a spectrophotometer. 
GSH- $\mathrm{P}_{\mathrm{X}}$ activity was detected by determination of the reduction of GSH, the GSH react with 5,5-Dithiobis (2nitrobenzoic acid), produce yellow colored compounds which were detected at $412 \mathrm{~nm}$ using a spectrophotometer (Lawrence and Burk, 1976).

Liver enzyme activity was expressed as units per $\mathrm{mg}$ of protein for liver tissue. The total protein content in liver tissue was determined using a protein assay kit (Nanjing Jiancheng Bioengineering Institute, China), according to the method of Lowry et al. (1951), using bovine serum albumin as a standard. Detailed procedures for the above detections were carried out according to the detection kit instructions.

\section{Statistical analyses}

All data were subjected to one-way ANOVA using Statistical Analysis Systems (SAS) statistical software package (Version 8e, SAS Institute, Cary, NC, USA). Means were considered significantly different at $p<0.05$.

\section{RESULTS}

\section{Histopathologic observations}

The results of the histopathologic examination of the liver are shown in Figure 1. There was no visible lesion
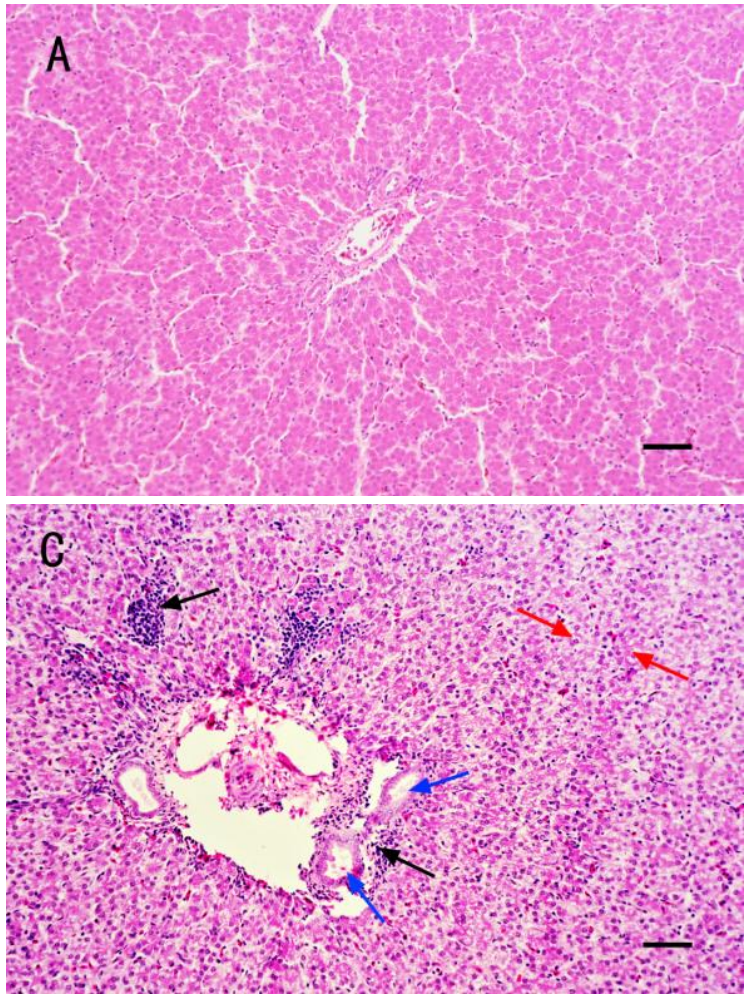

observed in livers of the control and $\alpha$-LA birds. Livers from birds fed with the diet containing $74 \mu \mathrm{g} / \mathrm{kg}$ of dietary $\mathrm{AFB}_{1}$ showed lesions such as mild vacuolar degeneration in hepatocytes, interlobular bile duct hyperplasia and lymphocytes infiltration (Figure 1C). Livers from broilers consuming the $\mathrm{AFB}_{1}$ plus $\alpha$-LA diet showed slight lymphocytes infiltration and slight vacuolar degeneration (Figure 1D). These results suggest a protective effect of $\alpha$ LA on aflatoxicosis.

\section{Plasma biochemical parameters}

Feeding diet containing $74 \mu \mathrm{g} / \mathrm{kg} \mathrm{AFB}_{1}$ to broiler chickens significantly increased the activity of plasma AKP $(\mathrm{p}<0.05)$ and reduced the levels of plasma TP $(\mathrm{p}<0.05)$ and ALB $(p<0.05)$ compared with normal chickens (Table 2). Plasma concentrations of CREA, UA, and $\mathrm{Ca}$ and the activity of $\gamma$-GT had no statistically significant differences between control and $\mathrm{AFB}_{1}$-treated birds ( $\mathrm{p}>0.05$; Table 2). Supplementation with $300 \mathrm{mg} / \mathrm{kg} \alpha-\mathrm{LA}$ in the $\mathrm{AFB}_{1^{-}}$ contaminated diet significantly improved the plasma values of TP and ALB concentrations and decreased AKP activities compared with chickens fed diet contaminated with $\mathrm{AFB}_{1}$ alone (Table 2). Birds fed diet containing $\alpha$-LA without
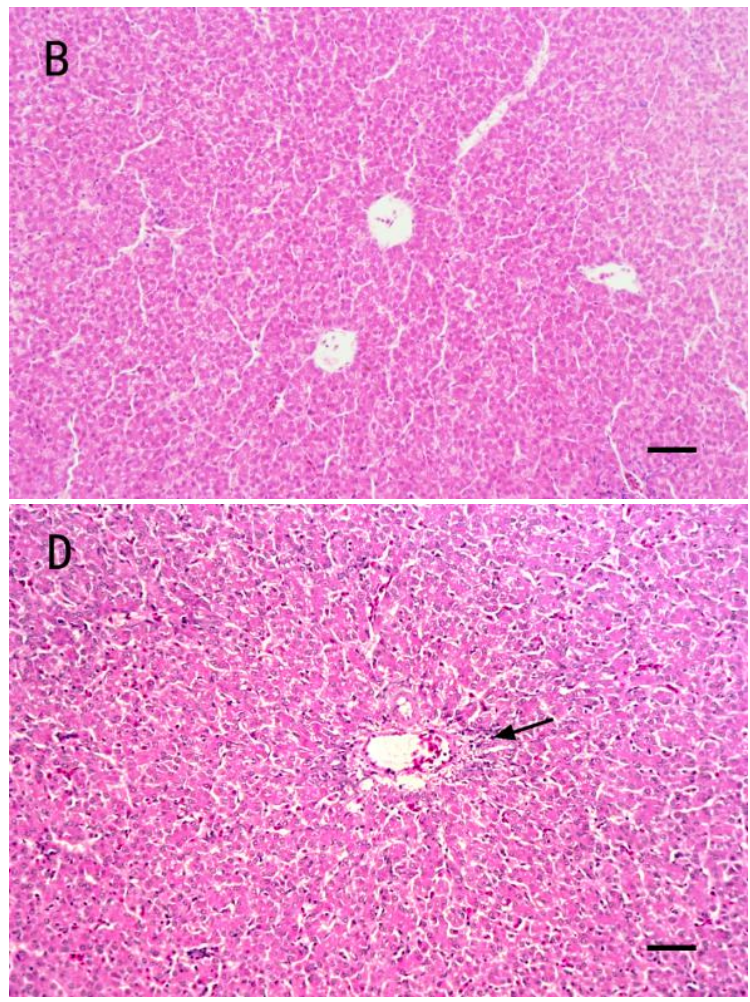

Figure 1. Photomicrographs (optical microscopy) of hematoxylin and eosin-stained broiler liver sections from different treatments. Normal liver architecture in control (A) and alpha-lipoic acid (ALA) (B) treated animals. Obvious liver lesion such as interlobular bile duct proliferation (blue arrow), lymphocyte infiltration (black arrow) and mild vacuolar degeneration in hepatocytes (red arrow) were observed in aflatoxin B1 ( $\left.\mathrm{AFB}_{1}\right)$-treated chick $(\mathrm{C})$. Slight lymphocytes infiltration (arrow) and slight vacuolar degeneration were visible in a chick given $\mathrm{AFB}_{1}$ plus ALA (D). Scale bar $=50 \mu \mathrm{m}$. Color version available in the online PDF. Original magnification: $\times 200$. 
Table 2. Effect of alpha-lipoic acid (ALA) on plasma chemistry in broilers fed a diet containing aflatoxin $\mathrm{B}_{1}\left(\mathrm{AFB}_{1}\right)(\mathrm{n}=8)$

\begin{tabular}{lccccc}
\hline Index & Control & ALA & AFB $_{1}$ & ALA+AFB $_{1}$ & SEM \\
\hline TP $(\mathrm{g} / \mathrm{L})$ & 19.02 & $26.11^{*}$ & $15.64^{*}$ & $20.11^{* *}$ & 0.82 \\
$\mathrm{ALB}(\mathrm{g} / \mathrm{L})$ & 17.02 & $19.88^{*}$ & $13.06^{*}$ & $16.65^{* *}$ & 0.61 \\
$\mathrm{AKP}(\mathrm{IU} / \mathrm{L})$ & 16.19 & 12.77 & $24.98^{*}$ & $15.70^{* *}$ & 1.13 \\
$\gamma-\mathrm{GT}(\mathrm{U} / \mathrm{L})$ & 19.88 & 18.88 & 19.75 & 19.00 & 0.49 \\
$\mathrm{UA}(\mu \mathrm{mol} / \mathrm{L})$ & 149.18 & 123.58 & 166.82 & 161.88 & 6.27 \\
$\mathrm{CREA}(\mu \mathrm{mol} / \mathrm{L})$ & 24.25 & 21.88 & 22.50 & 23.38 & 0.33 \\
$\mathrm{Ca}(\mathrm{mmol} / \mathrm{L})$ & 2.67 & 2.60 & 2.61 & 2.51 & 0.02 \\
\hline
\end{tabular}

SEM, standard error of the mean; TP, total protein; ALB, albumin; AKP, alkaline phosphatase; $\gamma$-GT, $\gamma$-glutamyl transferase; UA, uric acid; CREA, creatinine; $\mathrm{Ca}$, calcium.

$* \mathrm{p}<0.05$ compared to untreated control group. ** $\mathrm{p}<0.05$ compared to $\mathrm{AFB}_{1}$-treated group.

$\mathrm{AFB}_{1}$ had significantly increased the TP and ALB levels compared to those in control $(\mathrm{p}<0.05$; Table 2$)$.

\section{Liver metabolic enzyme and antioxidant index}

The effects of $\alpha$-LA on the liver metabolic enzymes and antioxidant index of broiler chickens exposed to $\mathrm{AFB}_{1}$ are shown in Table 3. As shown in Table $3, \mathrm{AFB}_{1}$-treated significantly decreased the liver GOT $(\mathrm{p}<0.05)$ and GPT $(\mathrm{p}<0.05)$ activities compared with the control group. The addition of $\alpha-\mathrm{LA}(300 \mathrm{mg} / \mathrm{kg})$ into the $\mathrm{AFB}_{1}$ diet increased the GOT $(p<0.05)$ activity compared with chickens fed $\mathrm{AFB}_{1}$ alone (Table 3). Compared with control chickens, $\mathrm{AFB}_{1}$ treatment decreased liver GSH-P $\mathrm{X}(\mathrm{p}<0.05)$ activity but had no any significant effects on the T-AOC concentration, T-SOD, CAT, and GR activities ( $p>0.05$; Table 3). The activity of GSH- $\mathrm{P}_{X}(\mathrm{p}<0.05)$ in liver of birds fed diet naturally contaminated with $\mathrm{AFB}_{1}$ and $\alpha$-LA (300 $\mathrm{mg} / \mathrm{kg}$ ) was significantly increased compared to that of birds fed diet contaminated with $\mathrm{AFB}_{1}$ alone (Table 3). The diet containing $\alpha$-LA significantly increased the T-SOD $(\mathrm{p}<0.05)$, GR $(\mathrm{p}<0.05)$ and GSH-P $\mathrm{X}_{\mathrm{X}}(\mathrm{p}<0.05)$ activities compared to the control group (Table 3 ), which showed that $\alpha$-LA can significantly improve liver antioxidant status.

\section{Content of malondiadehyde and glutathione in liver}

The results of biochemical analyses for liver MDA and
GSH levels are shown in Figure 2 and 3. Treatment with $\mathrm{AFB}_{1}$ caused an increase in MDA content $(\mathrm{p}<0.05$; Figure 2 ) while decreasing GSH level ( $p<0.05$; Figure 3 ) of liver as compared to the control. Furthermore, simultaneous $\alpha$-LA $\left(300 \mathrm{mg} / \mathrm{kg}\right.$ ) treatment to the $\mathrm{AFB}_{1}$ diet inhibited the elevation induced by $\mathrm{AFB}_{1}$ on the MDA level in liver and suppressed the effect of toxin on the GSH level and made

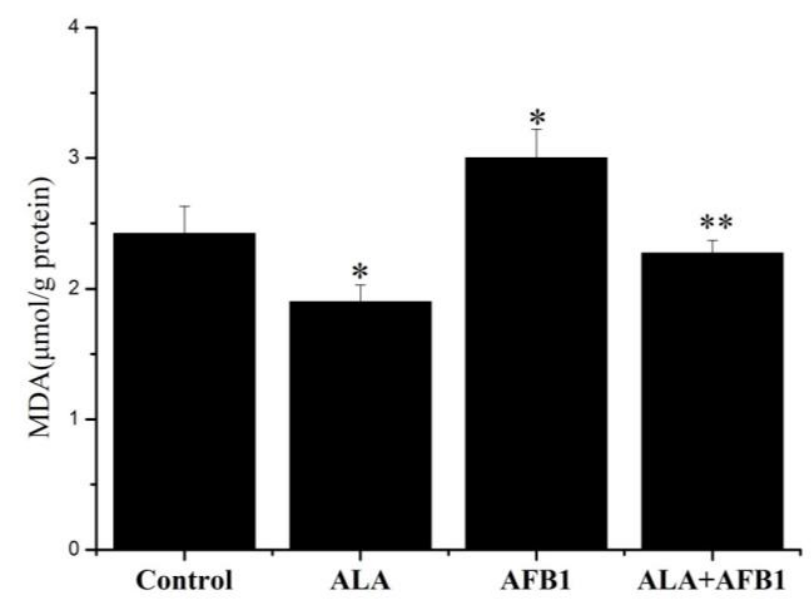

Figure 2. Effect of alpha-lipoic acid (ALA) on the content of malondiadehyde (MDA) in the liver of broilers fed a diet containing aflatoxin $\mathrm{B}_{1}\left(\mathrm{AFB}_{1}\right)(\mathrm{n}=8)$. $* \mathrm{p}<0.05$ compared to untreated control group. $* * \mathrm{p}<0.05$ compared to $\mathrm{AFB}_{1}$-treated group.

Table 3. Effect of Alpha-lipoic acid (ALA) on liver metabolic enzyme and antioxidant index in broilers fed a diet containing aflatoxin $B_{1}$ $\left(\mathrm{AFB}_{1}\right)(\mathrm{n}=8)$

\begin{tabular}{lccccc}
\hline Index & Control & ALA & AFB $_{1}$ & ALA+AFB $_{1}$ & SEM \\
\hline GOT (U/mg protein) & 55.86 & $79.53^{*}$ & $48.52^{*}$ & $57.13^{* *}$ & 2.24 \\
GPT (U/mg protein) & 10.27 & $11.05^{*}$ & $8.72^{*}$ & 10.00 & 0.29 \\
T-AOC (U/mg protein) & 1.55 & 1.86 & 1.34 & $1.73^{* *}$ & 0.06 \\
T-SOD (U/mg protein) & 183.36 & $210.36^{*}$ & 174.63 & $200.35^{* * * *}$ & 4.16 \\
CAT (U/g protein) & 243.64 & 257.86 & 242.21 & 241.54 & 10.16 \\
GR (U/g protein) & 3.30 & $4.50^{*}$ & 2.56 & 3.09 & 0.21 \\
GSH-P (U/mg protein) & 21.44 & $26.21^{*}$ & $14.99^{*}$ & $20.92^{* *}$ & 0.86 \\
\hline
\end{tabular}

SEM, standard error of the mean; GOT, glutamic-oxalacetic transaminase; GPT, glutamic-pyruvic transaminase; T-AOC, total antioxidant capacity; T$\mathrm{SOD}$, total superoxide dismutase; CAT, catalase; GR, glutathione reductase; GSH-P $\mathrm{X}$, glutathione peroxidase.

$* \mathrm{p}<0.05$ compared to untreated control group. $* * \mathrm{p}<0.05$ compared to $\mathrm{AFB}_{1}$-treated group. 


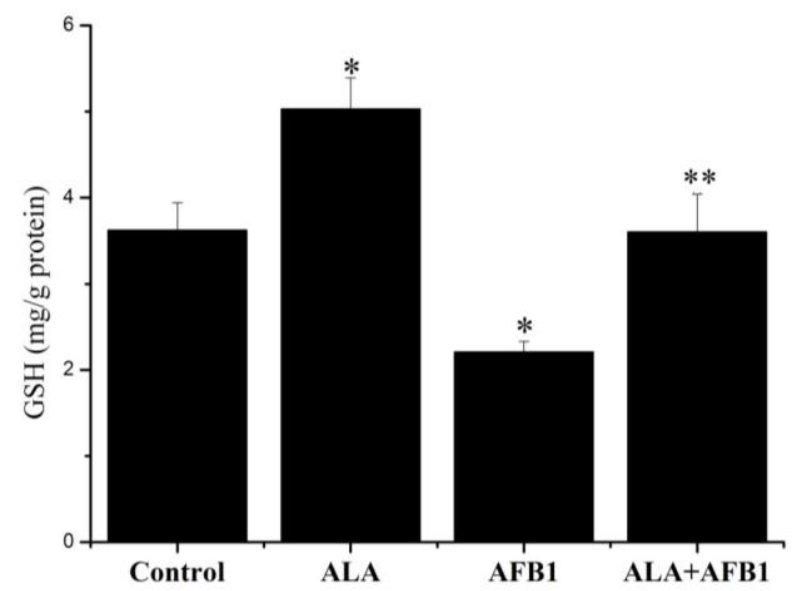

Figure 3. Effect of alpha-lipoic acid (ALA) on the content of glutathione $(\mathrm{GSH})$ in the liver of broilers fed a diet containing aflatoxin $\mathrm{B}_{1}\left(\mathrm{AFB}_{1}\right)(\mathrm{n}=8) . * \mathrm{p}<0.05$ compared to untreated control group. $* * \mathrm{p}<0.05$ compared to $\mathrm{AFB}_{1}$-treated group.

them approach to normal.

\section{DISCUSSION}

The presence of $\mathrm{AF}_{\mathrm{S}}$ in poultry diets is unavoidable because they are produced by ubiquitous fungi. Therefore, AFs pose a substantial risk of economic losses as well as human health problems. This is a particularly major concern in the poultry industry. However, the strategy of using food additives to protect farm animals from toxins may also provide new approaches to protecting human health (Williams et al., 2004). $\alpha$-LA has been used as a nutritional supplement and antioxidant in foods (Shay et al., 2009). In a previous study we reported that the chosen supplement amount of $\alpha-\mathrm{LA}(300 \mathrm{mg} / \mathrm{kg})$ in broilers is similar to human usual dose of $\alpha$-LA (Chen et al, 2011).

The effect of $\mathrm{AFB}_{1}$ diets on productivity parameters (BW gain, feed consumption, and feed conversion ratio) and the relative weights of livers did not show significant change compared with control diets ( $p>0.05$; data not shown). Similar results for chronic exposure to $\mathrm{AFB}_{1}$ have been reported previously (Oğuz et al., 2000; Magnoli et al., 2011). It is likely that these parameters (BW gain, feed consumption, feed conversion ratio, or organ development) were not sufficiently sensitive to the chronic effects of lower dose $\mathrm{AFB}_{1}$ when the birds were fed diets containing these toxins.

The liver is the main target organ for $\mathrm{AFs} . \mathrm{AFB}_{1}$ can cause abnormal liver enzyme activity and blood metabolism disorders. Regarding metabolism, a reduction in the contents of plasma TP and ALB, increase in plasma $\gamma$-GT and ALP activities, and decrease in liver GOT and GPT activities, have been reported to be indicators of liver toxicity (Shi et al., 2006). It has been reported that 50 to
$200 \mu \mathrm{g} / \mathrm{kg} \mathrm{AFB}_{1}$ in the diet changes the hematologicalbiochemical profiles in broilers (Oğuz et al., 2009). Here, $\mathrm{AFB}_{1}$ induced a significant decrease in levels of plasma TP and ALB and the activities of liver GOT and GPT, which indicate an adverse effect of $\mathrm{AFB}_{1}$ on liver function. Histopathological reports confirmed that the $\mathrm{AFB}_{1}$ significantly induced hepatic damage, thus supporting the observed biochemical alterations. These results also agree with a previous report of aflatoxicosis in rats (AbdelWahhab and Aly, 2003) and chickens that received $1 \mathrm{mg} / \mathrm{kg}$ $\mathrm{AFB}_{1}$ in the basal diet (Gowda et al., 2009). However, our results differ from others that reported no significant changes in serum biochemistry of broilers exposed to $\mathrm{AFB}_{1}$ ranging from 50 to $200 \mu \mathrm{g} / \mathrm{kg}$ (Abdelhamid et al., 1994; Magnoli et al., 2011). That may be because of the differences that exist in animal breed, age, nutritional or health status, and the time of exposure to $\mathrm{AFB}_{1}$. The toxin did not cause any statistically significant change in levels of the plasma UA and CREA (indicators of the toxic effects of $\mathrm{AFB}_{1}$ on renal tissue) in $\mathrm{AFB}_{1}$-exposed chickens, which may be because the liver tissue is more sensitive to chronic low dose aflatoxins than any other organs. However, supplementation with $\alpha$-LA almost completely abolished the induction of liver GOT and GPT activities when compared with $\mathrm{AFB}_{1}$-treated groups, suggesting that $\alpha$-LA could effectively suppress $\mathrm{AFB}_{1}$-induced liver dysfunction by inhibiting the reduction of liver amino transferases. Here, the decreases in TP and ALB concentrations in the $\mathrm{AFB}_{1^{-}}$ treated group suggest that the protein synthesis capacity in the liver was suppressed by $\mathrm{AFB}_{1}$, similar to our previous report in laying hens (Ma et al., 2012). Furthermore, these results also suggest that $\alpha$-LA can reverse the suppression.

Another threat of $\mathrm{AF}_{\mathrm{S}}$ on the body is potent hepatotoxicity as a result of antioxidant system damage. As with findings in rats (El-Agamy, 2010), chickens (Ozen et al., 2009) and quails (Essiz et al., 2006), an increase in the MDA content was found in the group of chickens treated with $\mathrm{AF}_{\mathrm{S}}$ alone. Measurement of MDA is widely used as an indicator of lipid peroxidation, and the increase in lipid peroxidation levels is associated with oxidative stress (Ozen et al., 2009), which may lead to pathological conditions and diseases (Niki, 2009). As previously observed by Naaz et al. (2007), an increase in the content of MDA may be secondary to the inhibition of enzymatic antioxidants (e.g., GSH-P $\mathrm{P}_{\mathrm{X}}$ activity) and depletion of non-enzymatic antioxidants (e.g., GSH) in liver in the $\mathrm{AFB}_{1}$-treated group compared with the control group chickens. Our study supports the hypothesis that oxidative stress may play a crucial role in $\mathrm{AFB}_{1}$-induced liver cell injury (Bedard and Massey, 2006; Sirajudeen et al., 2011).

Using $\alpha$-LA as a therapeutic agent for some diseases is because of the unique antioxidant properties of the $\alpha-\mathrm{LA} /$ 
dihydrolipoic acid redox couple. These attributes include its reactive oxygen species (ROS) scavenging ability and effects on the tissue content of the reduced forms of other antioxidants, including GSH, one of the most powerful cellular antioxidants (Bilska and Wlodek, 2005). Our previous studies also showed that $\alpha$-LA could enhance the activities of several enzymatic antioxidants, such as SOD and GSH-P $\mathrm{P}_{\mathrm{X}}$ and increase de novo synthesis of GSH (Chen et al., 2011). Several studies have reported that $\alpha$-LA can protect against hepatic oxidative stress, induced either by certain drugs or under various physiological and pathophysiological conditions (Abdel-Zaher et al., 2008; Zalejska-Fiolka et al., 2012). In view of these results, the effect of $\alpha$-LA on $\mathrm{AFB}_{1}$-induced liver oxidative stress was evaluated here. Our results demonstrate that the effects of $\mathrm{AFB}_{1}$ on the contents of MDA and GSH and the activities of antioxidant enzymes in the liver were reversed by $\alpha$-LA. The administration of $\alpha$-LA to the $\mathrm{AFB}_{1}$-contaminated diet significantly increased both the GSH level and the GSH-P $\mathrm{P}_{\mathrm{X}}$ activity compared with the group fed $\mathrm{AFB}_{1}$ alone. Moreover, our results showed a decrease in the MDA levels in the liver of birds fed $\mathrm{AFB}_{1}$-contaminated diet plus $\alpha$-LA when compared with those fed a diet containing $\mathrm{AFB}_{1}$ alone. The protective effect of $\alpha$-LA was indicated by the prevention of the lipid peroxide increase and the decreased enzymatic antioxidant activity and non-enzymatic antioxidant levels. Several similar mechanisms have been proposed to explain the protective efficacy of $\alpha$-LA against the liver oxidative stress induced by certain drugs in rats (Pari and Murugavel, 2004; Anandakumar et al., 2007; Abdel-Zaher et al., 2008) and $\mathrm{AFB}_{1}$-induced liver damage due to excessive production of lipid peroxidation in chicks (Karaman et al., 2010).

The GSH redox cycle is an important component of the antioxidant system in cells. The GSH and redox-modulating enzymes in tissues (such as GSH- $\mathrm{P}_{\mathrm{X}}$ in this study) play an important role in protecting cells from damage by reactive oxygen species. GSH-Px can catalyze the reducing of hydrogen peroxide directly to water and oxygen at the expense of reduced GSH (Jaeschke, 1995). The depletion of GSH may be due to the decreasing GSH-dependent enzyme GSH-Px, under oxidation stress status, leading to damage of lipids, proteins and DNA by the free radical. $\alpha$-LA increases GSH levels by improving the cellular availability of cysteine, which is the limiting substrate for GSH biosynthesis (Shay et al., 2009). In addition, GSH plays a critical role in protecting tissue damage from $\mathrm{AFB}_{1}$ by direct interaction with ROS or as a cofactor of enzymatic detoxification reactions for ROS (Larsson et al., 1994). Thus, the increase of MDA level, the depletion of intracellular GSH and the induction of $\mathrm{GSH}-\mathrm{P}_{\mathrm{X}}$ activity were found in the $\mathrm{AFB}_{1}$-treated group. These results indicate that the presence of increased levels of reactive oxygen species, hydrogen peroxide and lipid hydroperoxide may exceed the cellular defense capacity, thus resulting in oxidative stress. The dysregulated antioxidant balance in the liver of the $\mathrm{AFB}_{1}$-treated chickens may also correlate with severe liver function damage as shown by the reduction of liver GOT and GPT activities. However, these negative effects induced by $\mathrm{AFB}_{1}$ in the liver were inhibited by supplementation with $\alpha$-LA, indicating that $\alpha$-LA enhanced free radical scavenging and antioxidant status, further ameliorated the $\mathrm{AFB}_{1}$-induced oxidative stress. Furthermore, Sandhya and Varalakshmi (1997) also reported that $\alpha$-LA can prevent oxidative stress by increasing free radical scavenging capacity and inhibiting lipid peroxidation and GSH depletion, and by inducing of antioxidant enzyme activity. Together, the results described above suggest that $\alpha$-LA supplementation effectively improves defense against $\mathrm{AFB}_{1}$-induced oxidative stress.

In summary, our experiment clearly indicates that $\alpha$-LA has the ability to ameliorate $\mathrm{AFB}_{1}$-induced liver oxidative damage and may contribute to the inhibition of oxidation stress and maintenance of intracellular antioxidants status.

\section{ACKNOWLEDGMENTS}

We appreciate the support of Beijing Municipal Natural Science Foundation (Grant No. 6102014), the National Basic Research Program of China (Grant No. 2012CB124704), Key Projects in the National Science and Technology Pillar Program (Grant No. 2012BAD39B00) and National Science and Technology Program for the Rural Development in China (Grant No. 2011BAD26B00).

\section{REFERENCES}

Abdel-Wahhab, M. A. and S. E. Aly. 2003. Antioxidants and radical scavenging properties of vegetable extracts in rats fed aflatoxin-contaminated diet. J. Agric. Food Chem. 51:24092414.

Abdel-Zaher, A. O., R. H. Abdel-Hady, M. M. Mahmoud, and M. M. Y. Farrag. 2008. The potential protective role of alphalipoic acid against acetaminophen-induced hepatic and renal damage. Toxicology 243:261-270.

Abdelhamid Am, T. M., S. E. Dorra, A. E. Mansy Se, and A. E. Sallam. 1994. Effect of raising dietary protein, amino acids and/or energy levels as an attempt to alleviate severity of the chronic aflatoxicosis by broiler chicks. 2. Biochemical characteristics. Arch. Tierernahr. 46:347-355.

Anandakumar, P. P., S. P. Malarkodi, T. R. Sivaprasad, and G. D. Saravanan. 2007. Antioxidant DL-alpha lipoic acid as an attenuator of adriamycin induced hepatotoxicity in rat model. Indian. J. Exp. Biol. 45:1045-1049.

Bai, X. M., Q. G. Ma, L. H. Zhao, L. Xi, and C. Ji. 2012. Effects of alpha-lipoic acid supplementation on antioxidative ability and 
performance of sows and nursing piglets. J. Anim. Physiol. Anim. Nutr. (Berl). 96:955-961.

Barraud, L., T. Douki, S. Guerret, M. Chevallier, C. Jamard, C. Trepo, C. P. Wild, J. Cadet, and L. Cova. 2001. The role of duck hepatitis B virus and aflatoxin B1 in the induction of oxidative stress in the liver. Cancer Detect. Prev. 25:192-201.

Bedard, L. L. and T. E. Massey. 2006. Aflatoxin $\mathrm{B}_{1}$-induced DNA damage and its repair. Cancer Lett. 241:174-183.

Bennett, J. W. and M. Klich. 2003. Mycotoxins. Clin. Microbiol. Rev. 16:497-516.

Benzie, I. F. and J. Strain. 1999. Ferric reducing/antioxidant power assay: Direct measure of total antioxidant activity of biological fluids and modified version for simultaneous measurement of total antioxidant power and ascorbic acid concentration. Methods. Enzymol. 299:15-27.

Bilska, A. and L. Wlodek. 2005. Lipoic acid - the drug of the future? Pharmacol. Rep. 57:570-577.

Cai, Y., Z. Song, X. Zhang, X. Wang, H. Jiao, and H. Lin. 2009. Increased de novo lipogenesis in liver contributes to the augmented fat deposition in dexamethasone exposed broiler chickens (Gallus gallus domesticus). Comp. Biochem. Physiol. C. Toxicol. Pharmacol. 150:164-169.

Carlberg, I. and B. Mannervik. 1975. Purification and characterization of the flavoenzyme glutathione reductase from rat liver. J. Biol. Chem. 250:5475-5480.

Chen, P., Q. G. Ma, C. Ji, J. Y. Zhang, L. H. Zhao, Y. Zhang, and Y. Z. Jie. 2011. Dietary lipoic acid influences antioxidant capability and oxidative status of broilers. Int. J. Mol. Sci. 12:8476-8488.

Coulombe, R. A., J. A. Guarisco, P. J. Klein, and J. O. Hall. 2005. Chemoprevention of aflatoxicosis in poultry by dietary butylated hydroxytoluene. Anim. Feed Sci. Technol. 121:217225.

El-Agamy, D. S. 2010. Comparative effects of curcumin and resveratrol on aflatoxin B 1-induced liver injury in rats. Arch. Toxicol. 84:389-396.

Essiz, D., L. Altintas, and Y. K. Das. 2006. Effects of aflatoxin and various adsorbents on plasma malondialdehyde levels in quails. Bull Vet. Inst. Pulawy 50:585-588.

Gao, X., Q. Ma, L. Zhao, Y. Lei, Y. Shan, and C. Ji. 2011. Isolation of Bacillus subtilis: screening for aflatoxins $\mathrm{B}_{1}, \mathrm{M}_{1}$, and $\mathrm{G}_{1}$ detoxification. Eur. Food Res. Technol. 232:957-962.

Gowda, N. K. S., D. R. Ledoux, G. E. Rottinghaus, A. J. Bermudez, and Y. C. Chen. 2009. Antioxidant efficacy of curcuminoids from turmeric (Curcuma longa L.) powder in broiler chickens fed diets containing aflatoxin $B_{1}$. Brit. J. Nutr. 102:1629-1634.

Griffith, O. W. 1980. Determination of glutathione and glutathione disulfide using glutathione reductase and 2-vinylpyridine. Anal. Biochem. 106:207-212.

Henry, R. J., N. Chiamori, O. J. Golub, and S. Berkmans. 1960. Revised spectrophotometric methods for the determination of glutamic-oxalacetic transaminase, glutamic-pyruvic transaminase, and lactic acid dehydrogenase. Tech. Bull. Reg. Med. Technol. 30:149-166.

Jaeschke, H. 1995. Mechanisms of oxidant stress-induced acute tissue injury. Exp. Biol. Med. 209:104-111.

Karaman, M., H. Ozen, M. Tuzcu, Y. Ciğremiş, and F. Onder, Ozcan, K. 2010. Pathological, biochemical and haematological investigations on the protective effect of a -lipoic acid in experimental aflatoxin toxicosis in chicks. Br. Poult. Sci. 51: 132-141.

Kubena, L. F., R. B. Harvey, T. D. Phillips, and B. A. Clement. 1993. Effect of hydrated sodium calcium aluminosilicates on aflatoxicosis in broiler chicks. Poult. Sci. 72:651-657.

Larsson, P., L. Busk, and H. Tjälve. 1994. Hepatic and extrahepatic bioactivation and GSH conjugation of aflatoxin $\mathrm{B}_{1}$ in sheep. Carcinogenesis 15:947-955.

Lawrence, R. A., and R. F. Burk. 1976. Glutathione peroxidase activity in selenium-deficient rat liver. Biochem. Biophys. Res. Commun. 71:952-958.

Ledoux, D. R., G. E. Rottinghaus, A. J. Bermudez, and M. AlonsoDebolt. 1999. Efficacy of a hydrated sodium calcium aluminosilicate to ameliorate the toxic effects of aflatoxin in broiler chicks. Poult. Sci. 78:204-210.

Liu, Z. M., L. Q. Li, M. H. Peng, T. W. Liu, Z. Qin, Y. Guo, K. Y. Xiao, X. P. Ye, X. S. Mo, X. Qin. et al. 2008. Hepatitis B virus infection contributes to oxidative stress in a population exposed to aflatoxin B1 and high-risk for hepatocellular carcinoma. Cancer Lett. 263:212-222.

Lowry, O. H., N. J. Rosebrough, A. L. Farr, and R. J. Randall. 1951. Protein measurement with the Folin phenol reagent. J. Biol. Chem. 193:265-275.

Ma, Q. G., X. Gao, T. Zhou, L. H. Zhao, Y. Fan, X. Y. Li, Y. P. Lei, C. Ji, and J. Y. Zhang. 2012. Protective effect of Bacillus subtilis ANSB060 on egg quality, biochemical and histopathological changes in layers exposed to aflatoxin $B_{1}$. Poult. Sci. 91:2852-2857.

Magnoli, A. P., M. P. Monge, R. D. Miazzo, L. R. Cavaglieri, C. E. Magnoli, C. I. Merkis, A. L. Cristofolini, A. M. Dalcero, and S. M. Chiacchiera. 2011. Effect of low levels of aflatoxin $B_{1}$ on performance, biochemical parameters, and aflatoxin $\mathrm{B}_{1}$ in broiler liver tissues in the presence of monensin and sodium bentonite. Poult. Sci. 90:48-58.

Naaz, F., S. Javed, and M. Z. Abdin. 2007. Hepatoprotective effect of ethanolic extract of Phyllanthus amarus Schum. et Thonn. on aflatoxin $\mathrm{B}_{1}$-induced liver damage in mice. $\mathrm{J}$. Ethnopharmacol. 113:503-509.

National Research Council. 1994. Nutrient Requirements of Poultry. 9th edn. Natl. Acad. Press, Washington, DC.

Nibbelink, S. K. 1986. Aflatoxicosis in food animals: A clinical review. Iowa. State. Univ. Vet. 48:28-31.

Niki, E. 2009. Lipid peroxidation: Physiological levels and dual biological effects. Free. Radic. Biol. Med. 47:469-484.

Oğuz, H., V. Kurtoglu, and B. Coskun. 2000. Preventive efficacy of clinoptilolite in broilers during chronic aflatoxin (50 and 100ppb) exposure. Res. Vet. Sci. 69:197-201.

Ohkawa, H., N. Ohishi, and K. Yagi. 1979. Assay for lipid peroxides in animal tissues by thiobarbituric acid reaction. Anal. Biochem. 95:351-358.

Ozen, H., M. Karaman, Y. Cifremio, M. Tuzcu, K. Ozcan, and D. Erdag. 2009. Effectiveness of melatonin on aflatoxicosis in chicks. Res. Vet. Sci. 86:485-489.

Packer, L., E. H. Witt, and H. J. Tritschler. 1995. Alpha-lipoic acid as a biological antioxidant. Free. Radic. Biol. Med. 19:227-250.

Pari, L. and P. Murugavel. 2004. Protective effect of alpha-lipoic acid against chloroquine-induced hepatotoxicity in rats. J. Appl. Toxicol. 24:21-26.

Pier, A. C. 1992. Major biological consequences of aflatoxicosis in 
animal production. J. Anim. Sci. 70:3964-3967.

Rogers, S. A. 2003. Lipoic acid as a potential first agent for protection from mycotoxins and treatment of mycotoxicosis. Arch. Environ. Health 58:528-532.

Sandhya, P. and P. Varalakshmi. 1997. Effect of lipoic acid administration on gentamicin-induced lipid peroxidation in rats. J. Appl. Toxicol. 17:405-408.

Shay, K. P., R. F. Moreau, E. J. Smith, A. R. Smith, and T. M. Hagen. 2009. Alpha-lipoic acid as a dietary supplement: molecular mechanisms and therapeutic potential. Biochim. Biophys. Acta. 1790:1149-1160.

Shi, Y., Z. Xu, Y. Sun, C. Wang, and J. Feng. 2009. Effects of two different types of montmorillonite on growth performance and serum profiles of broiler chicks during aflatoxicosis. Turk. J. Vet. Anim. Sci. 33:15-20.

Shi, Y. H., Z. R. Xu, J. L. Feng, and C. Z. Wang. 2006. Efficacy of modified montmorillonite nanocomposite to reduce the toxicity of aflatoxin in broiler chicks. Anim. Feed Sci. Technol. 129:138-148.

Sirajudeen, M., K. Gopi, J. S. Tyagi, R. P. Moudgal, J. Mohan, and R. Singh. 2011. Protective effects of melatonin in reduction of oxidative damage and immunosuppression induced by aflatoxin $\mathrm{B}_{1}$-contaminated diets in young chicks. Environ. Toxicol. 26:153-160.

Surai, P. F. 2002. Natural antioxidants and mycotoxins. 1st ed. Nottingham, Nottingham University Press, Nottinggham UK, pp. 455-509.

Surai, P. F. 2006. Natural antioxidants in poultry nutrition: New developments. 16th European Symposium on Poultry Nutrition. Scotland, UK, pp. 669-676.
Trucksess, M. W., M. E. Stack, S. Nesheim, R. H. Albert, and T. R. Romer. 1994. Multifunctional column coupled with liquid chromatography for determination of aflatoxins B1, B2, G1, and G2 in corn, almonds, brazil nuts, peanuts, and pistachio nuts: Collaborative study. J. AOAC. Int. 77:1512-1521.

Umarani, M., P. Shanthi, and P. Sachdanandam. 2008. Protective effect of Kalpaamruthaa in combating the oxidative stress posed by aflatoxin $\mathrm{B}_{1}$-induced hepatocellular carcinoma with special reference to flavonoid structure-activity relationship. Liver Int. 28:200-213.

Wang, L., Y. Han, C. S. Kim, Y. K. Lee, and D. D. Moore. 2003. Resistance of SHP-null mice to bile acid-induced liver damage. J. Biol. Chem. 278:44475-44481.

Williams, J. H., T. D. Phillips, P. E. Jolly, J. K. Stiles, C. M. Jolly, and D. Aggarwal. 2004. Human aflatoxicosis in developing countries: a review of toxicology, exposure, potential health consequences, and interventions. Am. J. Clin. Nutr. 80:11061122.

Winterbourn, C. C., R. E. Hawkins, M. Brian, and R. Carrell. 1975. The estimation of red cell superoxide dismutase activity. J. Lab Clin. Med. 85:337-341.

Wogan, G. N. 1973. Aflatoxin carcinogenesis. In: Methods in Cancer Research (Ed. H. Bush). Academic Press, New York.

Zalejska-Fiolka, J., T. Wielkoszyński, S. Kasperczyk, A. Kasperczyk, and E. Birkner. 2012. Effects of oxidized cooking oil and $\alpha$-lipoic acid on blood antioxidants: Enzyme activities and lipid peroxidation in rats fed a high-fat diet. Biol. Trace Elem. Res. 145:217-221.

Zhang, Y., K. Hongtrakul, C. Ji, Q. G. Ma, L. T. Liu, and X. X. Hu. 2009. Effects of dietary alpha-lipoic acid on anti-oxidative ability and meat quality in Arbor Acres broilers. Asian Australas. J. Anim. Sci. 22:1195-1201. 